\title{
The role of ultrasound in detection of ovarian cysts confirmed by histopathology
}

\author{
Kawkab Noori Agha \\ Department of Radiology, Ibn Sena Teaching Hospital, Mosul, Iraq. \\ Correspondence: Kawkab Noori Agha. kawkabagha9@gmail.com. \\ (Ann Coll Med Mosul 2018; 40 (2): 59-62). \\ Received: $24^{\text {th }}$ Jun. 2018; Accepted: $9^{\text {th }}$ Sep. 2018.
}

\section{ABSTRACT}

Objective: The aim is to diagnose the ovarian cyst by ultrasound modality and confirmed this by histopathologic results.

Methods: Aprospective study on one hundred and fifty female patients in the period of one year (2009) in gyne-and obstetrical out patent clink.

Results: The patients examined and (150), ninty of these patient $(60 \%)$ have ovarian cysts. (48) patient $53 \%$. Their cyst resolved completely while (42) patient $47 \%$ are not respond to medical treatment and need surgical interference and these cyst are exposed to the histopathological assessment.

Conclusion: Sonography of the pelvic organs to detect ovarian cyst is a good imaging modality, quick and safe procedure, need no much preparation and easily predict the nature and type of the cyst and very easy methods to follow these patients.

Keywords: Ovarian cysts, Sonography.

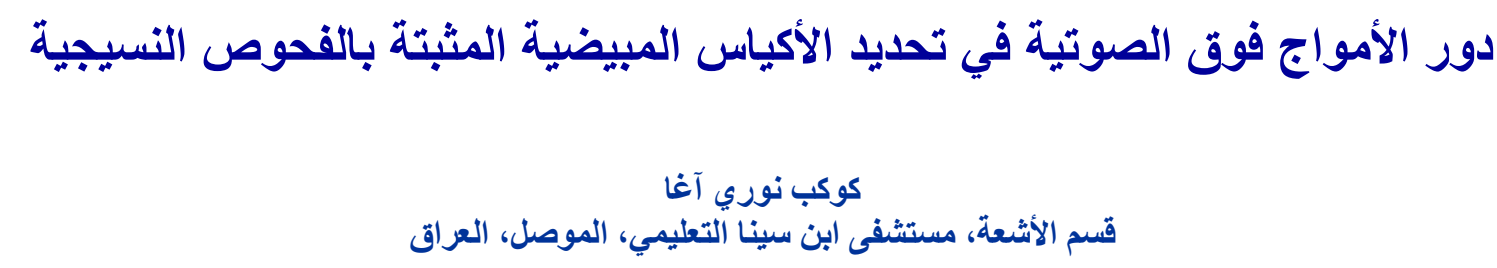

الخلاصة

الأهداف: يعد الفحص بالأمواج فوق الصوتية من أحدث و أهم الاساليب المستخدمة في فحص الأكياس المبيضية في الجهاز التناسلي

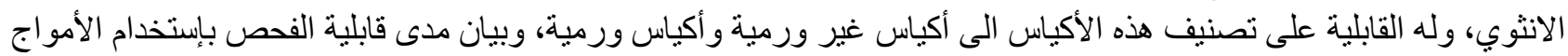

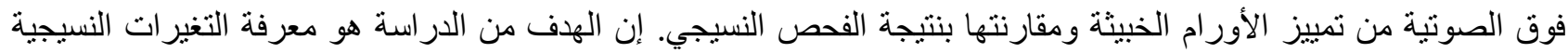

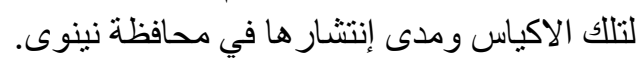
طريقة العمل: تناولت الدراسة (.010) مريضة راجعت قسم النسائية والتوليد في مستشفى (البنول التعليمي للولادة) تتراوح

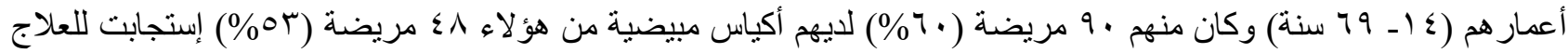

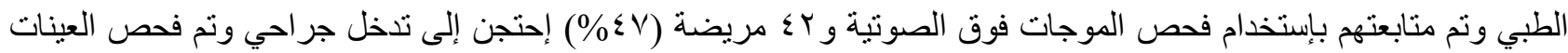

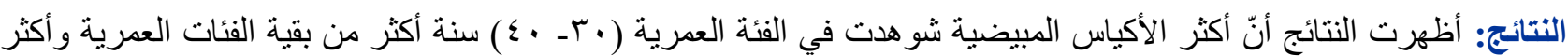

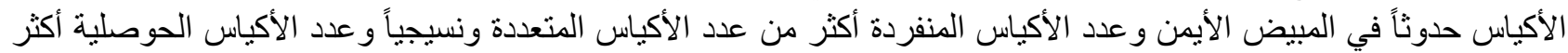

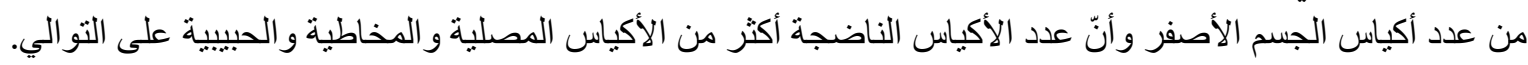

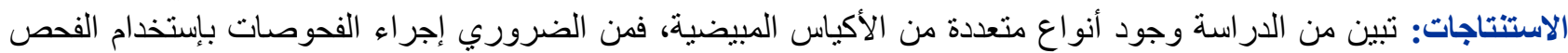

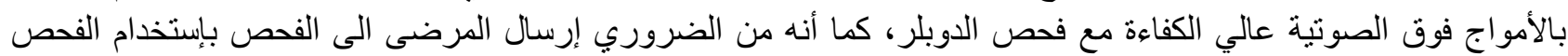

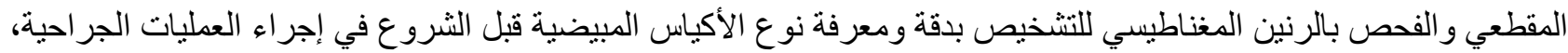
كما أنه من الضروري إجراء الفحوصات المختبرية و الدر اسة النسجية و المناعية لمنع حدوث أية مضاعفات الفيات. 


\section{INTRODUCTION}

$\mathrm{T}$ he ovarian cyst is fluid filled sac it can be noted as physiological cyst seen in menstrual cycle, or can be an growth benign or malignant cyst. They can be single cyst or poly cystic cyst. ${ }^{1}$

The functional ovarian cyst usually cause no symptoms and found incidentally on physical and imaging studies. These cyst are called follicular cyst and may rupture spontineously. ${ }^{2}$

Polycystic ovaries is an endocrine disorder effect $5 \%$ of women in the reproductive age. $^{3}$

Benign ovarian cyst account for $15-20 \%$ of ovarian neoplasm. Teratogenic and dermoid cysts are most common type of these benign tumour. ${ }^{4}$

Malignant ovarian tumor are one of the common malignancies all over the world. Most of them are asymptomatic till they have metastasized. ${ }^{5}$

Complicated Ovarian cyst can be presented in different way's, like, torsion, hemorrhage, rupture and infection. ${ }^{6}$

Sonography is the modality of choice in the evaluation of these cysts either through abdominal or transvaginal approach. ${ }^{7}$

Doppler Us is helpful for more details about the vascularity of the cyst and a risk of being malignant; because it shows clearly the vascularity of the cysts. In malignant ovarian cyst then will be abnormal vessels with a lower impedance of blood flow. ${ }^{8}$

\section{PATIENT AND METHOD}

A prospective study on one hundred and fifty female patients in a period of one year (2009) in Gyne obstetrical outpatient clinic. The age of the patients range from (14-69) year, the mean age is (41) year.

These patient examined by Philips Enviser H. D. 2009 Us machine using curved. Us probe 3.5 MHZs.

The patient were examined with full bladder, lying supine and abdominal Us is done and the results is Labeled. The Information's of the cyst are measured including the diameter, number, and there site too. Doppler Us is done and the sign of malignancy is fixed.

\section{RESULT}

The most frequent age group distribution for ovarian cyst is at (30-40) years. (Table 1)

From the (150) patient's examined (90) patients $(60 \%)$ have ovarian cyst of these patients who have the cyst are followed by repeated us examination during medical treatment (48 patient, $53 \%$ ) their cysts resolves completely, while (42 patients, $47 \%$ ) not responds to medical treatment, and need Surgical Interference, and these cysts exposed to histopathologial assessment. (Table 2) The distribution of the cysts and there sonographic features seen in Table $(3,4)$ and Fig. $(\mathbf{1}, \mathbf{2})$.

Table 1. Patient distribution according to age.

\begin{tabular}{ccc}
\hline Age (Years) & No. patient & \% out of 90 pat \\
\hline $\mathbf{1 0 - 1 9}$ & 08 & 8.8 \\
$\mathbf{2 0 - 2 0}$ & 17 & 19.0 \\
$\mathbf{3 0 - 3 9}$ & 28 & 31.1 \\
$\mathbf{4 0 - 4 9}$ & 18 & 20.0 \\
$\mathbf{5 0 - 5 9}$ & 14 & 15.5 \\
$\mathbf{6 0 - 6 9}$ & 05 & 5.6 \\
\hline Total & 90 & 100 \\
\hline
\end{tabular}

Table 2. Number of patients with a resolved ovarian cysts by medical treatment compared to those resolved surgically and other cases.

\begin{tabular}{lcc}
\hline \multicolumn{1}{c}{ Type of cyst } & $\begin{array}{c}\text { No of } \\
\text { patient }\end{array}$ & $\begin{array}{c}\% \text { out of } \\
90 \text { pt }\end{array}$ \\
\hline $\begin{array}{l}\text { Ovarian cyst resolved by } \\
\text { medical treatment }\end{array}$ & 48 & 53 \\
$\begin{array}{l}\text { Ovarian cyst resolved by } \\
\text { surgy }\end{array}$ & 42 & 47 \\
\hline Total & 90 & 100 \\
\hline
\end{tabular}

Table 3. Distribution of the cyst.

\begin{tabular}{lcc}
\hline Side & No of patient & \% out of $90 \mathrm{pt}$ \\
\hline Right & 61 & 67.7 \\
\hline Left & 29 & 32.1 \\
Total & 90 & 100 \\
\hline
\end{tabular}


Table 4. Ultrasonic features of ovarian cyst (90) patient.

\begin{tabular}{lc}
\hline Us. Finding & No of cyst \\
\hline An echoic cyst & 55 \\
Solid echoic & 7 \\
Mixed echogenicity & 18 \\
With Septation & 10 \\
Total & 90 \\
\hline
\end{tabular}
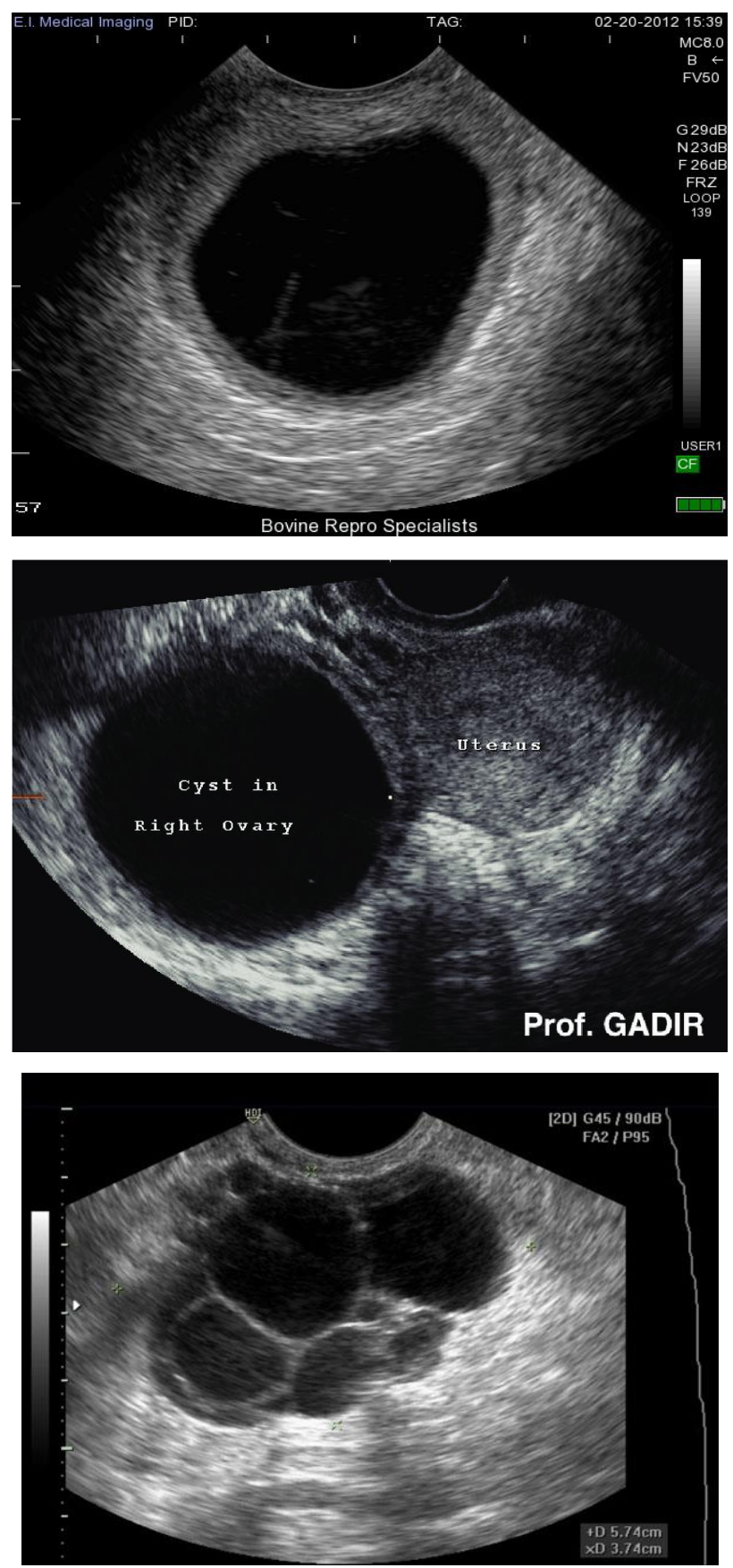

Figure 1. Ultrasonic pictures of different types of ovarian cysts.
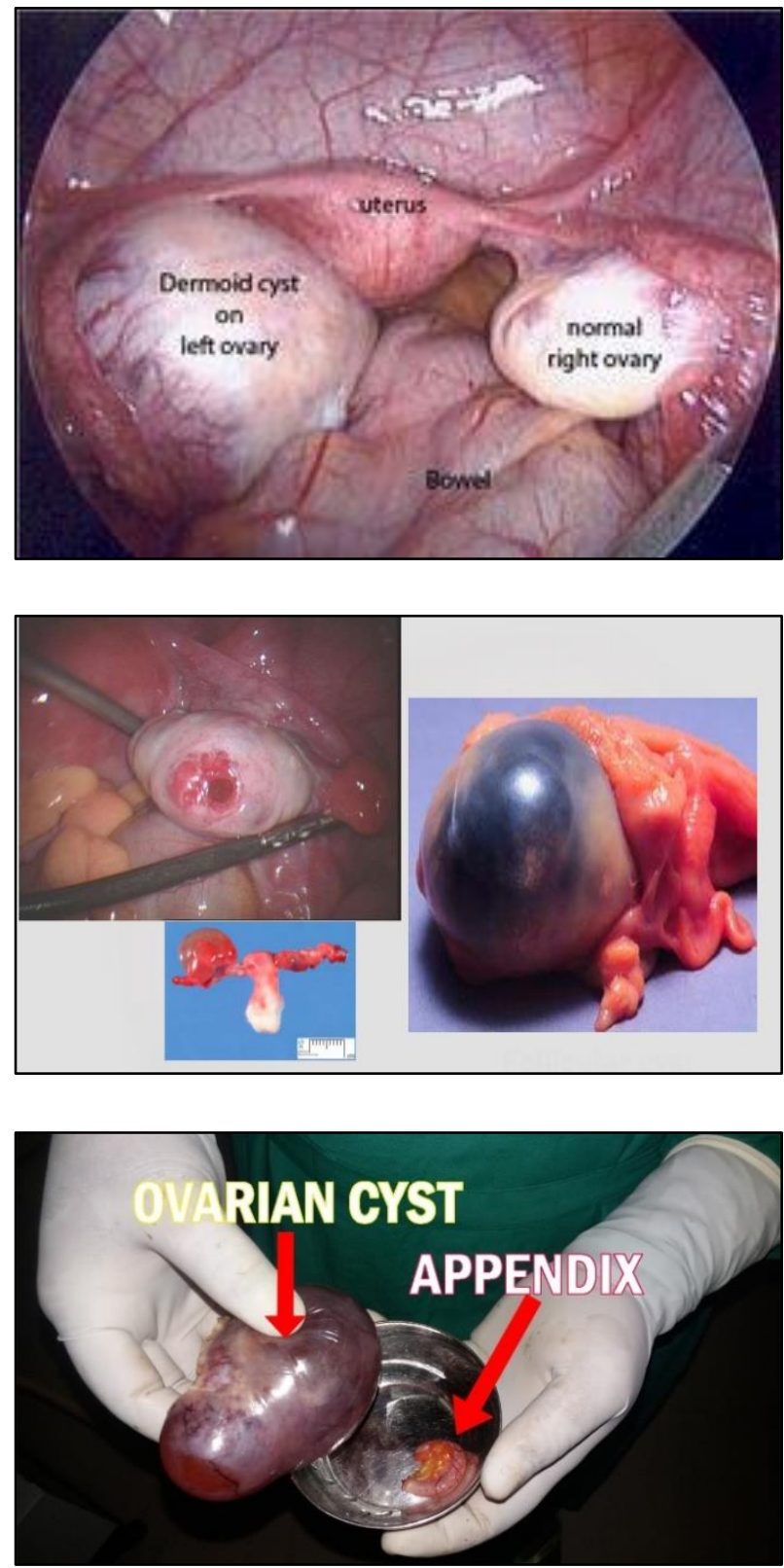

Figure 2. Ovarian cysts with their post-operative gross appearance.

\section{DISCUSSION}

Simple ovarian cyst can occur at the reproductive period. ${ }^{9}$ Malignant ovarian cysts are one of the major health problem which can present either symptomatic, or may be of vague symptoms or present with complication.

In this study must of the ovarian cyst are in the $4^{\text {th }}$ edcade of age, this result is in agreement with other studies as Tushar, k. et al 2005 found that the mean age for ovarian mass is 43 years ${ }^{10}$.

Regarding the distribution of the cysts, most cysts seen in this study are in the right ovary, and 
this fact was suggested by Ismail R. (2005) who found that the configuration of sigmoid colon which is curved (S) shaped, and the presence of the appendix in the right side facilitate for development of right ovarian cyst. ${ }^{11}$

In this study the cyst which shows mixed sonogencity and septated cyst proved in histopathology to be malignant cyst this result is in agreement with Valentine L. (2005) Series. ${ }^{12}$

The most common histological type of benign ovarian tumors in this study is serous cyst adenoma, and teratoma.

The overall sonographic sensitivity in diagnosing ovarian cyst was $88 \%$ and sepecifity of $(96 \%)$.

\section{CONCLUSION}

Sonography of the pelvic organ's to detect ovarian cyst is a good imaging modality, it is quick, safe, and applicable at any time, need no much preparation and easily predict the nature and type of the cyst and very easy modality for following the patient.

\section{REFERENCE}

1.Yousef F, Tajamal A, Sheikh S, Sultan F, Latif $R$. Symptomatology of functional ovarin cyst. The professional Journal 2004;11(3): 345.

2.Le T, Al Fayadh R, Mennard C, Hicks-Boucher W, Faught W, Hopkins $L$, et at. Variations in Ultrasound Reporting on patients referred for investigation of ovarin masses. J Obestet Gynaecol Can 2008; 30(10): 902903.
3.Tan S, Hahn S, Benson S, Diets T, Lahner H, Moeller L C, et al. Metformin improves polysystic ovary syndrome symptoms irrespective of per-treatment insulin resistance. European Journal of endocrinology 2007; 157(66):669-676.

4.Kumar G A, Rajeev M, Mohit A. Sonographic spectrum of ovarian dermoid. J Obstet Gynecol India 2005; 55(2):170-173.

5.Baloch S, Khashheli M, Malik A M, Sheeba A, Khushk I A. Clinical spectrum and management of ovarian tumours in young girls up to 20 years of Age. J Ayub Med coll Aboottabed 2008; 20(4):14-17.

6.Sorinola O, Cox C. Accidents to ovarian cysts. The obstetrician and gynecologist J 2002; 4(1):10-15.

7.A Prakash, Li T C, Ledger W L. The management of ovarian cysts in premenopausal women. $J$ The obstetrician and Gynaecologyist 2004; 6 (1) :12-15.

8.Teneriello M G, Park R C. Early Detection of ovarian cancer. CA cancer J clin 1995;45(2):71-87.

9.Nyati S, Bhosie A, Fonseca M. Serrous cyst adenoma complicating pregnancy. Bombay Hospital Journal 2009;51(4):534-535.

10.Tushar K, K Asaranti, Mohapatra PC. Intra-operative cytology of ovarian tumor. The Journal of obstetrics and gynecology of India 2005; 55(4):345- 348.

11.Ismail S R. An evaluation of the incidence of right sided ovarian cyst teratoma visualized on sonograms. Journal of diagnostic Medical sonography 2005; 21(4):336-342.

12. Valentin L, Ameye L, Testa A, Lecuru F, Bernard T P, Paladini $D$, et al. Ultrasound characteristics of different types of adnexal malignancies. J. Gynecologic Oncology 2005;102:41-48. 